\title{
El viento en la escollera: aire y agua
}

$$
\text { en la música popular uruguaya* }
$$

\section{Marita Fornaro Bordolli**}

El artículo propone un análisis de la presencia del aire en la música y el teatro musical popular de Uruguay, en especial de las décadas de 1980 y de 1990. Interesa establecer cómo las metáforas y alegorías del aire se encuentran con el agua física y simbólica de la bahía de Montevideo, ciudad que fue el puerto natural por excelencia del Atlántico Sur durante la Colonia y hasta hoy es punto de encuentros de tradiciones. A partir de la propuesta de Steven Connor en Matter of Air(2010), se atiende a la presencia simbólica del aire; se integran elementos de la antropología de las emociones y del análisis desde la retórica de las diversas artes. Para el caso de las canciones, se analizan los textos y su relación con la música, en especial aquellos rasgos vinculados con el contenido literario (características de la emisión vocal, instrumentación y arreglos), y en el caso de la murga, género de teatro musical carnavalesco, la vinculación entre literatura, música, coreografías, vestuario, escenografía y maquillaje. El análisis se profundiza para el espectáculo El planeador de la escollera Sarandí, producido por la murga Curtidores de hongos durante el carnaval montevideano de 2005, en que texto literario y vestuario se complementan en la producción de sentido, y para dos canciones interpretadas por Eduardo Darnauchans, figura relevante de la música popular uruguaya. Se incluye también una breve presentación de otras canciones que elaboran metafóricamente el paisaje visual y sonoro de la ciudad, con el aire como centro temático.

Palabras clave: música popular uruguaya, aire y metáforas, retórica de las artes performáticas murga uruguaya, teatro musical popular, Eduardo Darnauchans. doi 10.11144/javeriana.mavae15-2.evel

Fecha de recepción: 11 de noviembre de 2019

Fecha de aceptación: 3 de abril de 2020

Disponible en línea: 1 de julio de 2020

* Artículo de investigación. Resultado de varios proyectos de investigación financiados por la Comisión Sectorial de Investigación Científica de la Universidad de la República, el más destacado, Proyecto I+D Grupos "Música, escenas y escenarios en el Uruguay de los siglos XX y XXI" (2011-2015).

** Licenciada en Musicología, en Ciencias Antropológicas y en Ciencias Históricas por la Universidad de la República de Uruguay, Diploma de Estudios Avanzados (DEA) en Música y Espectáculo por la Universidad de Salamanca, Diploma de Estudios Avanzados en Antropología de las Sociedades Actuales por la misma universidad y doctora en Musicología por la Universidad de Valladolid. Coordinadora del Centro de Investigación en Artes Musicales y Escénicas, y profesora adjunta de la Escuela Universitaria de Música de la Universidad de la República.

ORCID: 0000-0002-9884-8995

Correo electrónico: maritafornaro@gmail.com

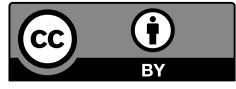




\section{Wind on the Breakwater: Air and Water in Uruguayan Popular Music}

The article proposes an analysis of the presence of air in music and popular musical theatre in Uruguay, especially in the 1980s and 1990s. It is interesting to establish how the metaphors and allegories of the air meet the physical and symbolic water of the bay of Montevideo, a city that was the natural port par excellence of the South Atlantic during the Colonial period and that is still a meeting point of traditions. From Steven Connor's proposal in Matter of Air (2010), the symbolic presence of air is addressed; elements of the anthropology of emotions and analysis from the rhetoric of the different types of art are integrated. The paper analyzes, in the case of songs, the lyrics and their relationship with music, especially those features linked to the literary content (characteristics of the vocal emission, instrumentation and arrangements), and, in the case of the murga, a genre of carnival musical theater, the link between literature, music, choreography, costumes, scenery and makeup. A more in-depth analysis is made for the show El planeador de la escollera Sarandí, produced by the murga, Curtidores de hongos, during the 2005 carnival of Montevideo, in which literary text and costumes complement each other in the production of meaning, and for two songs performed by Eduardo Darnauchans, a relevant figure of Uruguayan popular music. Also included is a brief presentation of other songs that metaphorically elaborate the visual and sound landscape of the city, with air as the thematic center.

Keywords: Uruguayan popular music, air and metaphors, rhetoric of the performing arts, Uruguayan murga, popular musical theatre, Eduardo Darnauchans

\section{O vento no cais: ar e água na música popular uruguaia}

0 artigo propõe uma análise da presença do ar na música e no teatro musical popular do Uruguai, especialmente nas décadas de 1980 e 1990. É interessante estabelecer como as metáforas e alegorias do ar se encontram com a física e simbólica da água da baía de Montevidéu, cidade que foi o porto natural por excelência do Atlântico Sul durante a Colônia e até hoje é um ponto de encontro de tradições.

Começando com a proposta de Steven Connor em Matter of Air (2010), a presença simbólica do ar é abordada; elementos da antropologia das emoções e da análise são integrados a partir da retórica de diversas artes. No caso das músicas, são analisados os textos e sua relação com a música, principalmente as características relacionadas ao conteúdo literário (características de emissão vocal, instrumentação e arranjos) e, no caso da murga, gênero de teatro musical carnavalesco, a ligação entre literatura, música, coreografia, figurinos, cenário e maquiagem. A análise é aprofundada para o espetáculo El planeador de la escollera Sarandí, produzido pela murga Curtidores de hongos durante o carnaval de Montevidéu em 2005, no qual textos e figurinos literários se complementam na produção de significado e para duas músicas interpretadas por Eduardo Darnauchans, figura relevante na música popular uruguaia. Também inclui uma breve apresentação de outras canções que metaforicamente elaboram a paisagem visual e sonora da cidade, tendo o ar como centro temático.

Palavras-chave: música popular uruguaia, ar e metáforas, retórica das artes performáticas, murga uruguaia, teatro musical popular, Eduardo Darnauchans. 


\section{Introducción}

$>$ La convocatoria de este número temático coincidió con ciertas reflexiones que llevaban tiempo anotadas a partir de mis trabajos sobre música popular uruguaya, en especial sobre la murga, género característico del carnaval desde comienzos del siglo XX, y sobre la estética de Eduardo Darnauchans, figura capital de la creación musical durante las décadas de 1980 y de 1990. La reflexión a priori ha devenido una investigación específica sobre la presencia de manifestaciones del aire en la música popular de Uruguay, y de cómo su cita literal o metafórica está muchas veces asociada a la imagen del agua.

El marco teórico de este trabajo parte de algunas de las propuestas de Connor (2010) quien se ocupa de "las maneras en que nuevos entendimientos del aire penetran en la experiencia social y en las experiencias humanas en sus modos de habitar el mundo" (14). ${ }^{1}$ Connor se muestra interesado, no en aislar el aire como un tema específico de reflexión en las diferentes disciplinas científicas, sino en algunas de las maneras en que el aire está involucrado en las formas de la vida social y en la imaginación, ya que considera que "el aire ha penetrado en todos los aspectos de la vida humana: ritual, mitología, medicina, agricultura y tecnología" (9). Dentro de este enfoque, el aire es investigado como un elemento mediador, y en ese sentido es que nos interesa plantearlo en este trabajo.

El aire aparece, en la mayoría de las manifestaciones de la música popular uruguaya que analizaré aquí, en vinculación con el agua. Esta relación es parte del planteo temático de este número, por cuanto en la convocatoria Sara Regina Fonseca concibe un "paradigma del aire" desde un "paradigma del agua", en especial para la danza. Aquí nos interesa cómo las metáforas y alegorías del aire se encuentran con el agua física y simbólica de la bahía de Montevideo. Varias de las obras analizadas tienen que ver con el Río de la Plata vivido como mar por quienes habitan las márgenes de este estuario que, en efecto, se siente marítimo por la ausencia de ribera opuesta (de manera sensorial, no geográfica). En este sentido, la producción que analizamos es exclusivamente montevideana: se ocupa, sobre todo, de las experiencias de aire y agua en el contexto de una ciudad puerto desde su origen histórico. Montevideo fue el puerto natural por excelencia del Atlántico Sur durante la Colonia, y hasta hoy es punto de llegadas, salidas, encuentros de personas y comercio. Es el lugar presente en todas las narrativas de inmigración durante el siglo XIX y la primera mitad del siglo XX; es el lugar donde se viven los vientos que llegan de aún más al sur.

El enfoque de mi trabajo prolonga la vocación interdisciplinaria del grupo de investigación en el que está inserto. ${ }^{2}$ Para el caso de canciones, analizaré aquí los textos y su relación con la música, en atención a aquellos rasgos vinculados con el 
contenido literario - características de la emisión vocal, instrumentación, arreglos- y, en el caso de la murga, género de teatro musical, la vinculación entre literatura, música, gestualidad, coreografías, vestuario, escenografía y maquillaje. El análisis parte del concepto antropológico de cosmovisión e integra elementos de la antropología de las emociones, que ha aportado nuevos caminos en este siglo, corriente que hemos aplicado a nuestra investigación sobre la obra de Jorge Drexler (Fornaro 2019). He partido de Le Breton (2013), quien atiende en especial a las culturas afectivas locales, consideradas una especie de "manual a disposición de los actores sociales" (75). En Beatty (2013), puede consultarse un panorama de los enfoques teóricos actuales sobre esta corriente, que incluye en la producción específica sobre música y emociones un clásico temprano, Feld (1982); ya en este siglo se destacan los trabajos de DeNora (2000) y Finnegann (2003) y de sociólogos como Hesmondhalgh (2008). La mayoría de estas investigaciones que se ocupan de emoción y música ponen el centro de interés en el receptor y en los efectos de la música sobre la personalidad individual; en este artículo, siguiendo el modelo que elaboré para la producción de Drexler, me centraré en el artista que trabaja desde la emoción y sus propios afectos, en este caso referidos a la identidad local. Finalmente, aplicaré, sobre todo en la primera parte del trabajo, el análisis desde la retórica que he tomado como marco teórico en mi investigación reciente sobre manifestaciones del carnaval uruguayo (Fornaro 2017).

El artículo se desarrolla en dos partes: en la primera, analizo la elaboración del concepto de aire en un espectáculo carnavalesco de 2005; en la segunda, atiendo al aire como tema en canciones producidas durante las décadas de 1980 y de 1990: me detengo en dos interpretaciones de Eduardo Darnauchans y rastreo el tema en otras figuras fundamentales de esas décadas.

\section{La murga y el aire: desde la escollera}

Como primer caso analizaré el espectáculo correspondiente a 2005 de la murga montevideana Curtidores de hongos, ${ }^{3}$ presentado como El planeador de la escollera Sarandí (https://www. youtube. com/watch?v=RwwnTluXeHo).

La murga surge como un género de teatro musical popular en el ámbito carnavalesco uruguayo a finales del siglo XIX; se caracteriza por un núcleo literario musical al que se agregan varias artes: teatro, danza, vestuario, maquillaje y escenografía. Constituye una reelaboración local de géneros españoles, en especial los interpretados por conjuntos de los carnavales de Andalucía, Extremadura y Castilla, de los que toma la estructura de su repertorio, el carácter grupal y masculino (este último aspecto muy modificado en el siglo XXI), la polifonía, el uso del contrafactum y la función de crítica de costumbres, autoridades y acontecimientos, sobre todo los correspondientes a cada ciclo anual entre carnaval y carnaval. Otras influencias están presentes en este género: del carnaval de Venecia, de los inmigrantes italianos y de la música afrouruguaya.

El espectáculo murguero incluye procedimientos discursivos y figuras de la retórica, como la ironía y el sarcasmo, la sátira y la parodia, la metáfora y la alegoría. Generalmente, se clasifica el género como humorístico; sin embargo, la investigación que he desarrollado durante décadas (Fornaro 1999, 2007, 2017) me ha permitido identificar otras vertientes de producción de sentido en la murga, correspondientes a manifestaciones líricas, épicas y trágicas.

Para introducir el caso seleccionado, transcribo un fragmento del texto, interpretado por un solista y el coro polifónico característico de la murga, que resume el tema del espectáculo. Los autores son Heber Martínez, Daniel Zieleniec, Diego Waisrub, Tabaré Aguiar y Freddy González, "letristas" profesionales del carnaval uruguayo (también han desarrollado otras profesiones asociadas al carnaval, como la dirección de conjuntos murgueros). 


\author{
El planeador: \\ Muchas veces me pregunto \\ adónde voy \\ si no tengo un plan \\ la vida se me va... \\ Nunca pude volar \\ Solo quise planear \\ Vivir... \\ este planear tan alto \\ que no poder \\ por la inmensidad \\ que siempre al final \\ vuelve a dejar la soledad \\ el fin... \\ Coro: \\ Planeador de los silencios \\ un eterno \\ de la gris y fría realidad \\ [...] \\ Cuanto tiempo perdí \\ por planear me olvidé \\ de vivir \\ Coro: \\ Planeador \\ es hora de volar!
}

Como es tradicional en la murga, el texto poético está planteado en primera persona por el personaje del planeador, mientras que el coro alterna sus intervenciones con el solista como comentarista, mentor o censor. Es importante el locus aludido ya desde el título: la escollera Sarandí es un gran rompeolas que se interna en el estuario del Río de la Plata en el extremo oriental de la bahía de Montevideo, lugar privilegiado para observar la ciudad y prolongación de una de las calles centrales de la Ciudad Vieja, es decir, del casco colonial de la metrópolis. Puede considerarse un lugar simbólico, con capacidad de resumen de la historia de la identidad portuaria de la ciudad y de su propio origen. Está presente en otras canciones populares uruguayas, incluso en piezas publicitarias.

En el espectáculo analizado, el vestuario es fundamental para la producción de sentido, por lo que me centraré en él para analizar el vínculo entre los elementos concretos, el planteo teórico del diseñador del vestuario y los contenidos metafóricos. El vestuario de El planeador... estuvo a cargo de Hugo Millán, diseñador y docente uruguayo, quien ha desarrollado una extensa trayectoria como vestuarista teatral y de murgas muy conocidas de Montevideo, entre ellas, Curtidores de hongos. Millán ha protagonizado momentos importantes en la evolución de la vestimenta murguera desde la última década del siglo $\mathrm{XX}$ : ha sido el autor de vestuarios que han definido una corriente orientada hacia la profesionalización de este oficio en el ámbito carnavalesco y hacia un trabajo vinculado con el desarrollo literario de los espectáculos. Trabajó con Curtidores de hongos desde 1995 hasta 2012, los primeros años con la diseñadora Soledad Capurro. Millán comenta su trabajo de comienzos del siglo XXI como una ruptura: 
Se concibió un vestuario vinculado a la temática y al cuerpo real, a la comodidad y a la teatralidad; más de un personaje, uno a uno. Si bien los veías como grupo, tenían particularidades según el cuerpo de cada uno. [...].

En los 80 se da una invasión del polyfom ${ }^{4}$ [...] como manera de generar volumen para la distancia. Es como el teatro griego: el volumen a distancia, los coturnos, el sombrero. [En la murga] era como un teletubbie. ${ }^{5}$ El tipo tenía un cierre atrás, entraba y eran todos iguales. $Y$ eso no me interesaba; me interesaba que si yo soy gordo se me viera como gordo; y el que era flaco se viera flaco, y el chiquito, chiquito. Y potenciar la gracia del cuerpo mismo, de cómo era cada uno. (comunicación personal, 16 de julio de 2016)

Sobre este vestuario en concreto comenta:

El año 2005 fue El planeador de la escollera Sarandí: cómo vivimos planeando, planeando, planeando, y nunca volamos. Ese era el tema. Incorporé el tema del movimiento, del vuelo del avión. Eran como unas turbinas. El sombrero tenía una hélice, un molinete de goma EVA; ${ }^{6}$ cuando ellos caminaban en el desfile [y durante las actuaciones] se movía solo. (comunicación personal, 16 de julio de 2016)

Siguiendo la tradición de diferenciar solista y coro, Millán optó por vestir al planeador con overol y cinchas de paracaidista, y al poeta delirante con el que dialoga, de levita cubierta de mariposas. "Todas las cosas están en el aire", "fueron los años más teatrales de esta murga" (comunicación personal, 10 de agosto de 2019). Y explica el desarrollo de los conceptos a nivel concreto:

Así como creé los molinetes a partir de la estructura de un cuadrado, para las vestimentas del coro utilicé tejido plástico de jardín, que, también a partir de un cuadrado, me permitía tornearlo para formar un propulsor con dos puntas que eran los alerones. Quería sugerir el aire con los molinetes y el propulsor.

Cuando pasan a la despedida, la vestimenta definitiva resulta producto de una crisis a la medianoche; los murguistas habían rechazado un cuello que era un remolino, porque consideraban que les molestaría en escena, y yo, ya desquiciado, primero caminando y luego frente a un maniquí de mierda, razoné: Si no puedes vencer al enemigo debes unirte. Y mandé al cuello a la espalda, quedó como una gran turbina, un remolino, una estrella, un gran sol, que, cuando ellos giraban, volaba. Todo es un remolino, con gajos rojos, naranja y amarillo.

El mismo motivo aparecía en la escenografía, con un molino de viento gigante. (comunicación personal, 10 de agosto de 2019; figuras 1 a 4). 

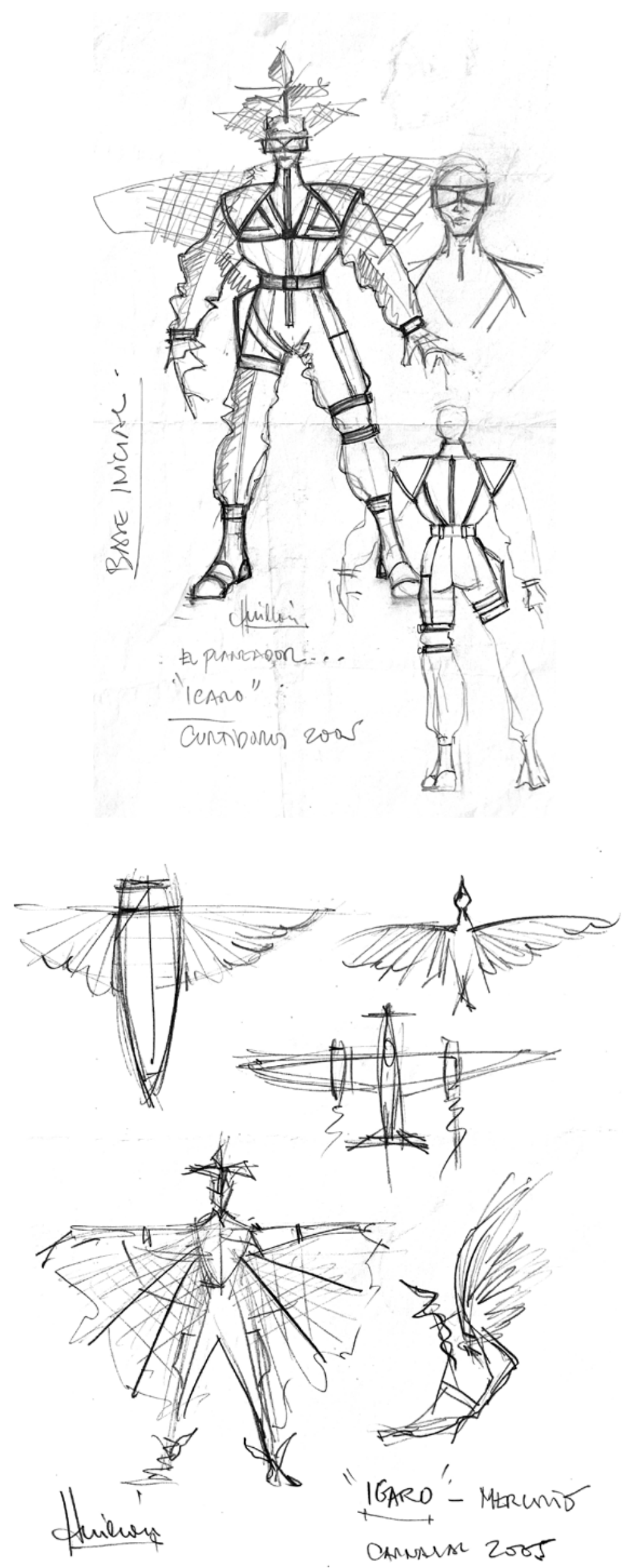

Figuras 2 y 3 . Bocetos de Hugo Millán para el Fuente: Bocetos de Hugo Millán. 
$176<$

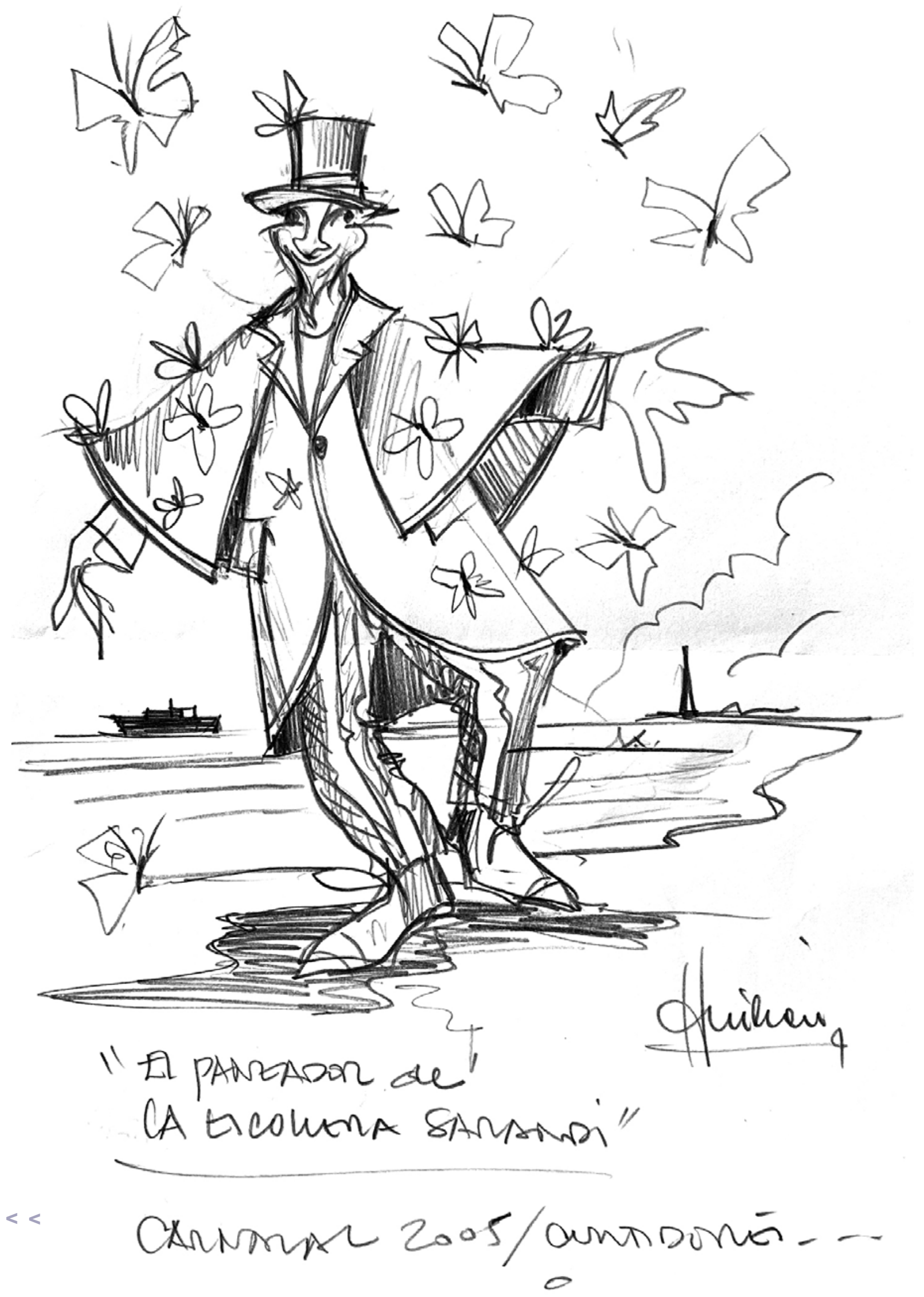


Entre planes y tantos delirios se nos fue la noche encallada en el mar del recuerdo vuelve a quedar una murga golpeando la puerta de otra despedida dejando en el camino su penúltimo plan.

El reloj del adiós ya nos dio su plan. El catalejo del tiempo quedó sin norte y fue por error, calidoscopio que nunca giró perdido sin luz ni color La magia se va, la vida se va, detrás del penúltimo plan El utilero guardó el disfraz en su frágil caja de cristal y ya se va volando sobre la multitud con su planeador frío y azul a buscar otra nueva esquina que quedó perdida, carnaval

nos quiere llevar con su verso fugaz.

En la puerta un camión nos espera rezongón... no hay motor que aguante tanta soledad.

El conductor fumando espera

no para de viajar en su triciclo imaginario harto de pedalear cruza nostalgias y alegrías tras la felicidad, pero llegó la despedida: algo funciona mal.

Pronto un enjambre de murgueros náufragos de agua y sal le pintarán una sonrisa entre la oscuridad cuando le dicen: vamo' arriba! Subite y arrancá! nunca te olvides que la vida solo es un viaje más.

[...]

No nos condenen, solo somos inquilinos de un pasado clandestino que otra vez nos convirtió en transeúntes del tiempo despiadado 


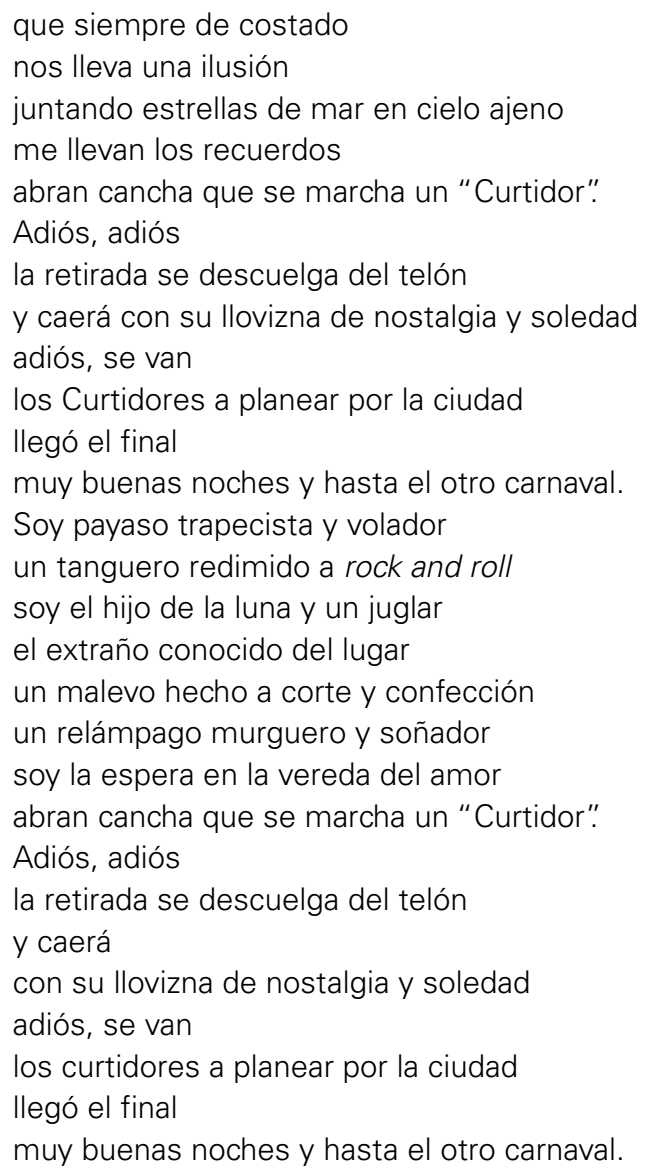

En este texto se juega con elementos afectivos y metáforas que vinculan el cielo y el aire, el aire que se respira, el aire ventoso y el aire como éter, es decir, la capa superior concebida desde la Antigüedad (Connor 2010, 31), con elementos acuáticos, para atender a los sentimientos predominantes en la despedida de un murguero: el juego alegría/tristeza, nostalgia, la "soledad de once meses" sin carnaval, el desamparo de la vida. Los afectos son elemento básico en la poesía murguera, que muchas veces transita entre sentimiento y sensiblería.

El caso de El planeador... recurre a los registros lírico y trágico. De los cuatro grandes núcleos temáticos que he identificado para la murga (temas filosóficos e ideológicos, la vida cotidiana, el carnaval y la murga, la música y el deporte), el repertorio 2005 de Curtidores de hongos pertenece al citado en primer lugar: la esencia del ser humano, la vida como viaje, la necesidad de concretar decisiones y sus implicancias. Para transmitir ese mensaje, utiliza fundamentalmente el recurso retórico de la alegoría. A efectos de un mejor entendimiento del análisis, me detendré en este procedimiento.

Según la retórica tradicional, establecida por Quintiliano y Cicerón, y continuada por los renacentistas, se considera la alegoría como una secuencia de metáforas secundarias que unidas dan lugar a una sola "metáfora extendida". La alegoría incluye la sinécdoque (figura retórica que consiste en designar una cosa o idea con el nombre de otra, con la que existe una relación de inclusión; puede ser la parte por el todo o el todo por la parte) y la metonimia (también un procedimiento retórico en que se designa una cosa o idea con el nombre de otra, con la que tiene relación de contigüidad, por dependencia o causalidad) (Fletcher 2002; Honig 1959). 
Fletcher (2002) considera la alegoría como un "medio proteico" (protean device) omnipresente en la literatura occidental; un lenguaje altamente codificado que, sin embargo, permite varios niveles de lectura, desde el literal hasta el de alta exégesis. Ve la alegoría como un modo de sustitución en que las cosas son representadas no de manera inmediata, sino por expresiones ambiguas que en sí mismas son diferentes de lo que significan en el ámbito alegórico. La alegoría ha sido estudiada en especial en la literatura y en las artes plásticas, y su carácter incluye un elemento predominantemente visual. En la literatura, se llama reiteradamente la atención sobre la persistencia de las alegorías medievales en los siglos siguientes. De hecho, en la Edad Media, el pensamiento alegórico era central en la cultura oficial y popular, alimentado desde el púlpito. La alegoría vuelve a experimentar un auge en el campo artístico durante el Barroco y el Romanticismo. Brown (2006) ha llevado a cabo un meticuloso estudio de manifestaciones alegóricas en el drama occidental en The persistence of Allegory: Drama and Neoclasicism from Shakespeare to Wagner. Por su parte, Baskins y Rosenthal (2007), al introducir los ensayos del libro Early Modern Visual Allegory: Emboding Meaning, resaltan la importancia de la presencia del modo alegórico en la esfera iconográfica de Occidente. Sobre un caso concreto y próximo, interesa el trabajo de Favoretto (2014) sobre los tipos de alegoría en la obra del argentino Charly García, centrado en sus textos. Favoretto identifica diferentes tipos de alegorías: políticas, esópicas, didácticas, de género, ópticas y heroicas. Si bien su taxonomía fusiona diferentes aspectos, como temas y funciones, resulta de utilidad para este análisis.

A partir de estas reflexiones teóricas, es posible considerar que el proceso de allegoresis en El soñador de la escollera Sarandí se desarrolla en torno al texto literario, el vestuario y la escenografía, en un ejemplo de encuentro de lenguajes. El planeador, en cuanto personaje, se ubica en un lugar paradigmático, la escollera del puerto de Montevideo que recibe los vientos del sur, del estuario. Es también el viento metafórico que mueve las hélices, representadas físicamente en tocados y escenografía, pero también elementos metafóricos, de manera que el recurso retórico, al expandirse, permite considerarlo como alegoría. Este recurso se complementa con la polisemia con que está empleado el verbo planear, y este sentido binario está en el centro de la producción de significado. El proceso de allegoresis podría resumirse así:

aire: llega desde la escollera y actúa sobre los objetos físicos

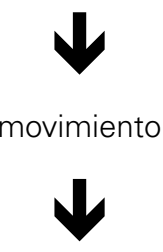

hélices, propulsor, remolino, turbina, molino

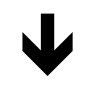

objetos concretos

recursos visuales

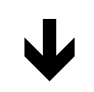

generadores de la alegoría

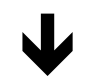

es necesario vivir, no solo planear (planificar) 
La inclusión de las hélices y del propulsor puede considerarse un procedimiento metonímico dentro de la allegoresis, ya que se designa una cosa o idea, el aire, por medio de otra, con la que, en este caso, hay una relación de contigüidad y causalidad; sin embargo, también podría leerse como sinécdoque: una parte, las hélices, por el todo, el planeador. Las hélices no se incorporan de manera artificial, sino que son parte de los tocados ("sombreros" en el lenguaje carnavalesco) que responden a una tradición heredada de Europa en cuanto al agigantamiento de los cuerpos, en este caso de los murguistas. En este espectáculo pueden observarse algunas de las estrategias de agigantamiento: las grandes hombreras y los tocados. Esta costumbre entronca con las festividades de gigantes y cabezudos de diversos países europeos, entre ellos España; es recogida en las figuras de papel maché de los tablados tradicionales del carnaval uruguayo (Fornaro 2018) y aún está en práctica en el carnaval de Cádiz, el carnaval español más relacionado con el uruguayo. La teatralidad de la murga ubica en el centro del espectáculo el cuerpo representado y el cuerpo en performance. Desde el antiguo ritual de salir envueltos en sábanas que fungían de disfraces hasta la sofisticación de los vestuarios de diseñadores como Millán, estas prácticas han recorrido un complejo camino en la integración al espectáculo y en la producción de mensajes dentro de él. El trabajo de Millán ejemplifica el nivel del planteamiento teórico elaborado para la concepción del vestuario y los accesorios a partir de un núcleo temático propuesto por los responsables de una murga.

En consecuencia, en El planeador... está presente la alegoría literaria, de tema filosófico, que adquiere una dimensión visual a través de vestuario y escenografía, y que en esta dimensión podría considerarse una alegoría dinámica (hélices, aire, por tanto, movimiento). Es también una alegoría con un fin moral, al estilo de las usadas en el mundo religioso occidental: no es posible solo planear, sino que se debe vivir.

\section{Eduardo Darnauchans: el aire, lugar del vuelo}

El aire aparece asociado a la tecnología — a la posibilidad humana de volar - en la producción de Eduardo Darnauchans, una figura clave de la música popular uruguaya, en especial durante el periodo de dictadura cívico-militar sufrida por Uruguay entre 1973 y 1985, si bien las acciones represivas están presentes en los años anteriores de la década de 1970.

Eduardo Darnauchans (Montevideo, 1953-2007) desarrolla su carrera a partir de su vinculación con el llamado Grupo de Tacuarembó, liderado por el poeta Washington Benavides (Tacuarembó, 1930-Montevideo, 2017) e integrado por poetas y músicos como Héctor Numa Moraes, Víctor Cunha, Carlos da Silveira, Eduardo Larbanois, Carlos Benavides, Eduardo Milán, entre otros. Su biografía ha sido elaborada por Couto (1993), Díaz (2008) y Rodríguez (2012); Sabaj (2017) se ha ocupado de su poesía; por mi parte, he analizado aspectos de su obra y también editado críticamente dos de sus fonogramas (Fornaro 2009, 2013).

Darnauchans se destaca muy temprano y comienza su viaje hacia Montevideo y los estudios de grabación luego de ganar un concurso local en Tacuarembó —donde vive parte de su infancia y su adolescencia - a los 17 años. Su discografía puede dividirse en tres etapas principales. Los inicios de su carrera incluyen el disco doble Alicia maravilla/Niñez de luz (1970) y los vinilos que fundamentan su popularidad en Uruguay: Canción de muchacho (1973), Las quemas (1974) y Sansueña (1978). En este periodo, Darnauchans es autor de la música de la mayoría de las canciones que interpreta, pero solo de una pequeña parte de los textos. Su trabajo se centra en la musicalización de poesía y en la interpretación. Canción de muchacho supone el descubrimiento por la crítica; Las quemas se gesta en medio de las peripecias de 
dictadura, exilio en Argentina y clima de censura; Sansueña es el descubrimiento por parte de un público más amplio, el eje a partir del cual se despliega su talento poético. La plenitud compositiva e interpretativa llega con Zurcidor (1980), Nieblas \& neblinas (1985), El trigo de la Iuna (1989) y Noches blancas (1999). Se da luego un periodo sin producción, y un retorno a la grabación ya en el cambio de siglo; Entre el micrófono y la penumbra (2001, recital en vivo), Canciones sefaradíes (2004, recital en vivo) y El ángel azul (2006). A esta discografía deben agregarse dos recopilaciones: Sin perder el tiempo (1991, con temas desde 1978 a 1982); Darnauchans 811/2 - Raras \& casuales (2003, recopilación de grabaciones desde 1972 a 1992) y tres ediciones digitales de vinilos. Se dispone también de dos ediciones póstumas de recitales: Ámbitos, grabado con Fernando Cabrera en el Teatro Solís en 1991 (2008) y Nosotros tres, recitales realizados con Jorge Galemire y Eduardo Rivero en 1976 (2010). Y, finalmente, mi trabajo de edición crítica, concretado sobre Las quemas (2008) y Sansueña (2009).

Este recorrido artístico está acompañado de una biografía trágica desde la infancia, con una herencia familiar de trastornos psiquiátricos que le acompaña toda la vida, y un periodo de riesgo físico y psíquico durante la dictadura. Darnauchans escribe en escasas ocasiones sobre temas manifiestamente políticos, pero su pertenencia al Partido Comunista determina su detención, su libertad vigilada y su exilio en Buenos Aires, aspectos que influyen decisivamente en su producción artística. En todo este proceso, Darno, como se le llamaba, surge como compositor de música para textos de poetas uruguayos, latinoamericanos y españoles.

Darnauchans se definía a sí mismo como songwriter, negándose a pensarse como poeta o músico de manera aislada. Su producción implica un concepto de canción en tanto producto artístico que supone la unión de por lo menos tres expresiones artísticas: poesía, música y performance. Darnauchans no escribe poesía como tal; le interesa componer e interpretar canciones (figura 5).

La obra de Darno y su propio discurso, para el que está disponible un DVD que resume un curso que organizamos en la Universidad de la República en 2004, evidencia variadas influencias: la de Benavides, el maestro que lo acompaña desde su adolescencia hasta su muerte; el ambiente fronterizo de las ciudades donde transcurre su su niñez y juventud, que incluye abundantes elementos de la cultura erudita y popular de Brasil (este universo de influencias es fronterizo en diferentes sentidos: por la atención a la producción literaria y musical de Brasil, y por el fluido ir y venir entre lo académico y lo popular), de elementos de la poesía y música medievales, la producción isabelina, el folk y el country escocés y estadounidense, la chanson francesa; Bob Dylan, Donovan Leicht, el francés Antoine, Angelo Branduardi, Fabricio D’André, Leonard Cohen; las aparentemente antagónicas presencias de The Beatles y de los conjuntos del llamado folclore argentino de la década de 1960; y los poetas y dramaturgos latinoamericanos que Benavides acercaba al grupo.

Los aviadores (https://Www.youtube.com/watch?v=RKoJ647QQ4Q) forman parte del disco compacto Zurcidor, es decir, de la que podría considerarse la fase media de su carrera. Este vinilo implica un cambio muy significativo en la obra de Darnauchans, con una apertura a nuevas propuestas tímbricas en los arreglos, entre ellas, los de Fernando Cabrera, no solo en Los aviadores, sino en la magnífica Orquesta de señoritas del argentino Raúl González Tuñón con música del propio Darnauchans. La canción que nos ocupa es un caso en que el aporte creativo del Darno está en la interpretación. El texto es del poeta y filósofo uruguayo José Carlos Seoane (Tacuarembó, 1959) y la música es de Fernando Cabrera (Montevideo, 1956), otro creador fundamental, con quien Darnauchans se asoció en variados recitales, quien, además, ha sido influencia determinante en nuevas generaciones de músicos, entre ellos, Jorge Drexler (Fornaro 2019). Como ya he anotado, la presencia de Cabrera en la canción analizada es múltiple: autor de la música, es también responsable del arreglo de especial peso creativo y el intérprete de la guitarra que acompaña la voz de Darnauchans. 
El aire aquí adquiere el carácter de lugar habitado por los protagonistas, que son imaginados en la claridad - aire vinculado a la luz- con pensamientos cotidianos antes de la tragedia: el recuerdo de un libro, de una mujer.

Interrogado sobre el interés de Darnauchans por los aviadores, Víctor Cunha —poeta, productor de su obra, compañero de creación de toda una vida, fotógrafo que documentó momentos cruciales - anota elementos para ese interés: la admiración por Antoine de Saint-Exupéry, cuando El principito aún no había sufrido banalización; la admiración por otro libro, Vuelo nocturno; y la construcción de un personaje por parte de Darno —un personaje sobre otro personaje- quien con una chaqueta de aviador y rengueando se presentaba como un capitán inglés, elaborando anagramas a partir de su nombre.

Darnauchans vuelve a ocuparse del tema en Oración para aviadores (Oração para Aviadores), texto del poeta brasileño Manuel Fonseca, traducción y música de Darno. Esta canción está incluida en Darnauchans 81/2 - Raras \& casuales, por su particularidad de no encontrarse en la obra editada; es grabación en vivo de un recital de 1977 (https://www.youtube.com/watch? v=IzfnWpZIOns). Por sus características puede vincularse a la presencia de Washington Benavides en la obra del cantautor. Benavides fue su maestro desde el aula formal de la enseñanza secundaria en la ciudad de Tacuarembó hasta su muerte, pasando por infinitas instancias, como las reuniones y las comunicaciones a distancia en una época en que los integrantes del Grupo solían enviarse casetes con letras o músicas. También practicaban comúnmente, según testimonio del propio Benavides y del compositor y cantor popular Héctor Numa Moraes, ${ }^{7}$ el ejercicio de tomar un libro de poesía e ir componiendo músicas para cada poema, músicas que se dejaban en el olvido, como mero ejercicio, o que se guardaban en casetes, algunos de ellos todavía conservados. Hemos podido seguir este procedimiento es sus "vestigios" históricos —esas frágiles grabaciones en casetesy también en el presente: Benavides y Numa Moraes fueron los guías de un "Taller de creación de poesía y música popular" en la Universidad de la República (2009-2017), ${ }^{8}$ que hasta hoy, en ausencia de sus fundadores, reproduce y amplía este "ejercicio." Víctor Cunha confirma que el origen de esta canción está en ese tipo de práctica a partir de un libro de Manuel Bandeira.

Manuel Bandeira [Manuel Carneiro de Sousa Bandeira Filho, Recife, 1886-Río de Janeiro, 1968) integró la primera generación del modernismo brasileño, y esta condición debe haber sido determinante para el interés de Darnauchans, quien opta por cantar una parte de la letra en español y otra en portugués, que en algunos momentos se transforma en portuñol, el dialecto del portugués característico de la frontera norte de Uruguay; este aspecto resume el universo lingüístico de su infancia y adolescencia, y el mundo literario que le acerca, temprano, Benavides.

El poema de Bandeira ha sido musicalizado también por dos compositores académicos, Manuel Lacerda y Silvia Berg. Es una manifestación de la vertiente de catolicismo popular presente en la producción de este poeta, con varias obras que invocan figuras destacadas del santoral (santa Teresa, san Francisco y santa Clara de Asís, santa Teresita de Jesús), advocaciones de la Virgen María (Nossa Senhora da Boa Morte), rituales como el Día de Difuntos (Caldas Cervinskis y Martis de Mendonça 2008). Santa Clara no tiene un vínculo oficial con la aviación (la santa protectora de esta actividad es la Virgen de Loreto; Clara lo es de la televisión y las telecomunicaciones, por decisión papal de 1958); el vínculo debe leerse desde la relación entre aire y claridad, que nos interesa en especial por su contenido metafórico. Llama la atención la decisión de Darnauchans de musicalizarlo, ya que, aunque de cosmovisión cristiana, no tenía una inclinación religiosa (fue miembro del Partido Comunista de Uruguay). Sin embargo, el artista no tenía problemas en que en su obra convivieran aspectos religiosos con posiciones anarquistas.

El texto resume aspectos fundamentales del concepto de aire, con un juego de aliteración entre los términos Clara y claread, el cual refuerza el vínculo con el poder del nombre de la santa, que en la hagiografía católica se vincula a una anunciación sobrenatural a su madre, en que habría sido establecida la brillantez del hijo a nacer: "Clara" se vincula etimológicamente a inteligencia y celebridad. 
Santa Clara, claread.

estos aires.

Dadnos vientos regulares,

de felicidad.

Estos mares, estos aires

claread.

Santa Clara, dadnos sol, haz bajar la cerrazón

Alumbrad a nuestros ojos

en la cerrazón

Estos montes y horizontes

Claread $^{9}$

Santa Clara, no mau tempo

sustentai

nossas asas.

A salvo de árvores, casas,

e penedos,

nossas asas governai.

Santa Clara, clareai.

afastai

todo risco.

Por amor de São Francisco, vosso mestre, nosso pai,

Santa Clara, todo risco

dissipai.

Santa Clara, clareai. ${ }^{10}$

El texto de Bandeira toma la forma de oración tradicional; la estructura de verso libre, característica de su producción modernista, juega con el concepto de aire claro, de claridad como protección sobre elementos físicos, geográficos (aires, mares, acantilados, montes, paisajes humanos, horizontes); la oposición sol y cerrazón, niebla y el más metafórico "alumbrad a nuestros ojos." La oposición claridad/tinieblas, tan cara al cristianismo, subyace en todo el poema.

La música de Darnauchans apela a la sencillez instrumental, como es usual en su producción: su guitarra propone un breve preludio que hace pensar en una milonga campesina, que queda en suspenso para asumir la forma canción sin un género específico. El estribillo condensa la relación entre el nombre de la santa y el ruego.

Este es un texto cantado con melismas al final de algunos versos, además de vocales prolongadas como en Los aviadores. Como ya hemos anotado (Fornaro 2013), este creador irrumpe desde su juventud en el canto silábico característico de la música popular uruguaya con juegos melismáticos hasta hoy únicos, que luego complementará con otros efectos, como hemos visto en el análisis anterior. En varias de sus canciones, Darnauchans, no solo trabaja melismas a la manera tradicional que heredamos desde la Antigüedad judeocristiana, es decir, sobre las vocales, sino que los ejecuta sobre "eles", "emes" y "enes" sostenidas en el tiempo. 


\section{Aire y agua: los vientos de una ciudad puerto}

En expresiones de la música popular uruguaya de estéticas muy diferentes, la experiencia del aire en su manifestación climática - tema de muy antiguos antecedentes en las artes- se vincula, como señalé en la introducción, con el agua de la bahía de Montevideo, del estuario del Río de la Plata. Los vientos marítimos son parte de la identidad urbana, ya cantados por Jaime Roos (Montevideo, 1953), uno de los músicos más prolíficos e influyentes a lo largo de décadas (sobre Jaime Roos, véase Alfaro 1987, 2017). En Durazno y Convención (vinilo Mediocampo, 1984; https://Www.youtube.com/watch?v=Nr-kvNnSU94), con ritmo de candombe, Roos dibuja el paisaje en movimiento de la costa, con el hombre a la intemperie, envuelto, abrazado, por los vientos:

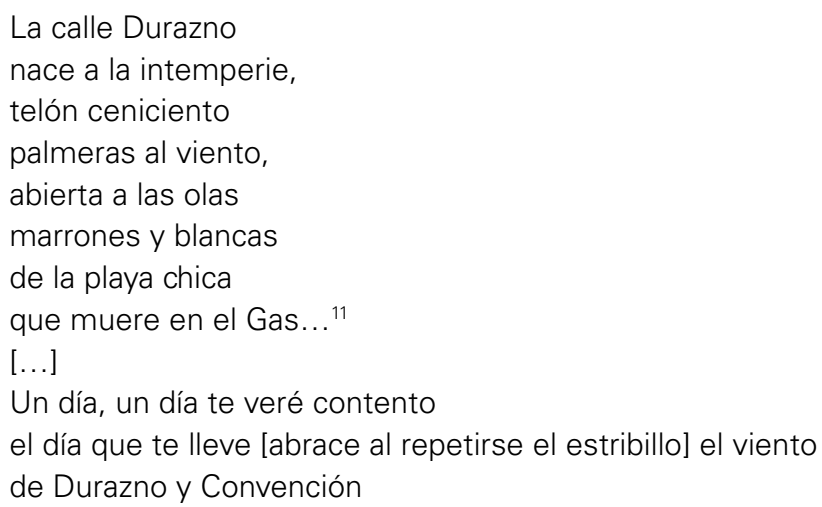

Y en Los Olímpicos (https://www.youtube.com/watch?v=z4btW12vq_0), una de las manifestaciones tempranas de la canción murguera (género desprendido de la murga), la paradoja de los emigrantes es planteada en la contradicción entre la bonanza económica y las carencias afectivas. Y entre esas carencias, el emigrante "extraña el aire del puerto / cuando anuncia el temporal". El cantautor, con ritmo de murga, apela a los sentidos (la sensación del viento en el cuerpo, el "olor a mar" que todo montevideano considera la más infalible de las predicciones meteorológicas).

Esta unión de aire y agua está presente en Una canción a Montevideo de Mauricio Ubal (Montevideo, 1959), presentada a un concurso del Gobierno de Montevideo para crear un himno a la ciudad, en 1993, y triunfadora de ese concurso. Ubal es un músico de larga trayectoria, coautor de una de las canciones de resistencia emblemáticas en Uruguay, A redoblar.

La canción, con ritmo de candombe y digresiones hacia otros géneros, fue grabada con participación de muchos intérpretes uruguayos, entre ellos, quienes ya han sido objeto de análisis en este artículo: Eduardo Darnauchans y Fernando Cabrera. Transformada en un himno conocido, Una canción a Montevideo es otro ejemplo de la frecuencia del lenguaje metafórico en los textos de la música popular uruguaya: 
Con su voz marinera encantada viene un viento inventor de avenidas viene un cerro patrón de miradas que va hundiéndose ahí en la bahía vienen sueños, vienen pueblos...

Con su voz de boliches y grillos vienen soles de ropa tendida ciudadelas de muros heridos preguntando qué fue de la vida vienen cielos, vienen fuegos...

Viene amar

viene amar

viene amar a este Montevideo

Vienen los sombreros

llenos de tranvías

vienen los tambores

llenos de glicinas

Vienen las sirenas

la radio prendida

y en el medio del temporal...

viene un tango en un estuche de malvón

a llorar porque ha perdido la ciudad

Viene amar

viene amar

viene amar a este Montevideo

Vienen navidades

gorriones antiguos

cantores de carnaval

Esos techos de rambla infinita

esas voces con techos de nada

todo viene a esta mansa bahía

mar de fondo de nuestras palabras

viene, duele,

cae en la hondura

de cada soledad

Viene amar

viene amar

viene amar a este Montevideo

Viene mar

viene amar

viene mar de este Montevideo

Es interesante el juego entre los términos amary mar, que, además de planteados en el texto, se confunden en la experiencia de escucha. Nuevamente está presente el resumen de identidades y afectos: el puerto receptor de pueblos, diásporas del terror y de la esperanza, como las define Appadurai (2001). Aquí el viento crea la ciudad; la urbe, con sus caídos muros coloniales, tiene voz de marinero, en una paradoja de género. $Y$ el poeta describe, como en los casos anteriores, un paisaje sonoro propio de ella, con tambores afrouruguayos, murgueros y radios. La reflexión del propio creador remite nuevamente a la idea de aire, vuelo, viaje en el tiempo, ya planteado en el espectáculo murguero analizado. 
Nunca me había presentado a un concurso así, ni volví a hacerlo después. Fue un desafío. Primero trabajé en la rítmica, que tendría que ser el "piso" de la canción. Elegí finalmente el ritmo de candombe porque me pareció lo más genuino y original si queremos presentar el sonido musical de este rincón del mundo. Además me lo planteé como un tema de justicia para con aquellos que nos trajeron ese ritmo maravilloso, hipnótico y guerrero. La melodía me llevó un mes concretarla. La letra fue lo más difícil de todo. Debería ser algo sencillo pero a su vez poético. Traté de evitar la enumeración de lugares o sitios, porque era imposible incluirlos a todos. Finalmente, en las últimas horas antes que venciera el plazo de presentación, pude cerrar la idea por la cual navegaría la letra de la canción: esa voz que, como un "viento inventor de avenidas", viene, vuela, crea, viaja en el tiempo, nos atraviesa, nos ama y nos vuelca al mar. (Granizo 2019)

\section{Estos mares, estos aires, claread...}

Finalmente, queda por anotar el aspecto iconográfico, visual, de estas producciones y de su recepción. Más allá del cambio en la recepción que significa que un espectáculo de murga pueda ser revisitado infinitas veces mediante DVD, en YouTube y en Instagram (una nueva vida que cambia el carácter anual y único de cada producción ), en el caso de las canciones existen videoclips oficiales, mash-up de usuarios (el caso de Los aviadores, con un video en blanco y negro, por ejemplo) e iconografía de vinilos y CD. El caso de Una canción a Montevideo es representativo, pues la Intendencia de Montevideo editó un CD con el tema ganador del concurso como pista única, y el arte gráfico resume varias de las ideas que han sido ejes en este trabajo: una fotografía del puerto intervenida con dibujos de nubes y del río, la ciudadela histórica de Montevideo, un mapa antiguo de su bahía... y dibujos de tres sobresalientes pintores uruguayos, Pedro Figari, Rafael Barradas y Joaquín Torres-García. El resultado, algo ecléctico, ejemplifica el carácter de mosaico musical que Ubal buscó para su canción.

En resumen, he propuesto hasta aquí un recorrido que ha llevado a encontrar un universo alegórico y metafórico donde aire o aire y mar están anclados en una pertenencia identitaria asociada a Montevideo, ciudad puerto cuya historia aparece resumida en la fusión de tradiciones literarias, musicales y teatrales que dan vida a las manifestaciones analizadas. Los "vientos del sur", tan citados en las canciones populares pasan a ser, en el proceso que los transforma, en tema de producción artística, el motor que mueve hélices, molinos, mujeres y hombres que reciben su abrazo y que llegan, con sus afectos, a "amar a ese mar". 
1. Traducciones de la autora.

2. Grupo I+D "Música y Sociedad" (GIDMUS), Centro de Investigación en Artes Musicales y Escénicas, Universidad de la República, Uruguay.

3. Las murgas uruguayas suelen tener nombres humorísticos, y los conservan durante su existencia, a diferencia de grupos españoles como los de Cádiz, que lo cambian en cada carnaval. Curtidores de hongos es una de las murgas más antiguas del país constituida en 1912 por obreros que cantaban cerca de una curtiembre. De ahí el nombre jocoso: en vez de curtir los cueros, curten los hongos que surgen en ellos (Alfaro 2012).

4. Masa plástica espumada, de uso común en artículos domésticos.

5. Personaje de Teletubbies, programa de televisión destinado a los niños de edad preescolar, emitido por la cadena BBC entre 1997 y 2001, también emitido en Uruguay.

6. Etilvinilacetato, muy utilizado en artesanías y vestuario.

7. Testimonios brindados durante el curso organizado en la Universidad de la República, 2004 (Fornaro 2009).

8. Taller producido por el antropólogo Antonio Díaz en los proyectos de Bienestar Universitario de la Universidad de la República. El taller, al que asisten estudiantes, docentes, egresados, funcionarios administrativos y sus familiares, ha producido dos CD con selecciones de los textos musicalizados.

9. Santa Clara, clareai / Santa Clara, clareai / estes ares. / Dai-nos ventos regulares / de feição. / Estes mares, estes ares / clareai. / Santa Clara, dai-nos sol. / se baixar a cerração, / AlumiaimMeus olhos na cerração. / Estes montes e horizontes / Clareai.

10. Hemos respetado el texto escrito del poema, sobre el que Darnauchans hace modificaciones, algunas vinculadas con el portuñol.

11. Edificio de la Compañía del Gas de Montevideo. 


\section{[REFERENCIAS]}

Alfaro, Milita. 1987. Jaime Roos: El sonido de la calle. Montevideo: Trilce. 2012. Curtidores de hongos: Misteriosa leyenda. Montevideo: Museo del Carnaval.

. 2017. Jaime Roos, el montevideano. Montevideo: Planeta.

Appadurai, Arjun. 2001. La modernidad desbordada: Dimensiones culturales de la globalización. Montevideo: Trilce.

Baskins, Cristelle y Lisa Rosenthal, eds. 2007. Early Modern Visual Allegory: Emboding Meaning. Aldershot: Ashgate.

Beatty, Andrew. 2013. "Current Emotion Research in Anthropology: Reporting the Field". Emotion Review 5 (4);414 . 422.

Brown, Jane K. 2006. The Persistence of Allegory: Drama and Neoclasicism from Shakespeare to Wagner. Philadelphia: University of Pensylvannia Press.

Caldas Cervinskis, André y Wilma Martis de Mendonça. 2008. "Religiosidade e brasilidade em Manuel Bandeira". Prolingua 2 (2): 72-79. https://periodicos.ufpb.br/ojs2/index.php/prolingua/ article/view/13405/7609

Connor, Steven. 2010. The Matter of Air: Science and Art of the Ethereal. Londres: Reaktion Books.

Couto, Tabaré. 1993. Eduardo Darnauchans: Los espejos y los mitos. Montevideo: Arca.

DeNora, Tia. 2000. Music in Everyday Life. Oxford: Clarendon Press.

Díaz, Nelson. 2008. Memorias de un trovador: Conversaciones con Darnauchans. Montevideo: Planeta.

Favoretto, Mara. 2014. Charly en el país de las alegorías: Un viaje por las letras de Charly García. Buenos Aires: Gourmet Musical.

Feld, Steven. 1982. Sound and Sentiment Birds, Weeping, Poetics, and Song in Kaluli Expression. Durham: Duke University Press.

Finnegann, Ruth. 2003. "Music, Experience, and the Anthropology of Emotion". En The Cultural Study of Music: An Introduction, editado por Martin Clayton, Trevor Herbert y Richard Middleton, 181-192. Londres: Routledge.

Fletcher, Angus. 2002. Alegoría: Teoría de un modo simbólico. Madrid: Akal.

Fornaro Bordolli, Marita. 1999. "'Los cantos inmigrantes se mezclaron...': La murga uruguaya: Encuentro de orígenes y lenguajes". El Sonido de la Cultura: Textos de Antropología de la Música 1516, 139-170. https://www.redalyc.org/pdf/822/82200607.pdf

- 2007. “Repertorios en la murga hispano-uruguaya: Del letrista a la academia". Pandora: Revue d'etudes hispaniques 7: 31-48.

- 2008. "Las quemas: Entre el agua y el humo, la misma sed". En Las quemas de Eduardo Darnauchans. Montevideo: Sondor. CD-ROM.
—. 2009. "Eduardo Darnauchans: El estar siempre". En Sansueña edición 30 años. Montevideo: Sondor. CD-ROM.

2013. “Voz, música, performance: El caso de Eduardo Darnauchans en la música popular uruguaya". Revista del Instituto de Investigación Musicológica Carlos Vega 27: 121-150.

- 2017. "Más allá del humor: Articulación de lenguajes artísticos y procedimientos retóricos en la murga hispano-uruguaya". Tesis de doctorado, Universidad de Valladolid.

- 2018. "The Uruguayan Carnival Stages of the First Half of the Twentieth Century between Transgression and 'Measured Joy'". Music in Art International Journal for Music Iconography 43 (1-2): 123-140.

- 2019. "En la puerta giratoria: La visibilidad de Jorge Drexler en la prensa española". Cuadernos de Etnomusicología 13: 184-216. http://www.sibetrans.com/etno/cuaderno/31/cuadernosde-etnomusicologia-n-13

Granizo. 2019. "Una canción a Montevideo" cumplió 25 años. Consultado: 17 de octubre de 2019. http://granizo.uy/medio-y-medios/unacancion-a-montevideo-cumplio-25-anos/

Hesmondhalgh, David. 2008. "Towards a Critical Understanding of Music, Emotion and Self-Identity". Consumption, Market \& Culture 11 (4): 329-343

Honig, Edwin, 1959. Dark Conceit: The Making of Allegory. Míchigan: Northwestern University Press.

Le Breton, David. 2013. "Por una antropología de las emociones". Revista Latinoamericana de Estudios sobre Cuerpos, Emociones y Sociedad 4 (10): 69-79.

Rodríguez, Marcelo. 2012. Darnauchans: Entre el cuervo y el ángel. Montevideo: Perro Andaluz Ediciones.

Sabaj, Silvia. 2017. Darnauchans: Poesía y compromiso de un cantor popular uruguayo. Montevideo: Ediciones del Empedrado. 